\title{
Group randomized trial of teaching tobacco-cessation counseling to senior medical students: a peer role-play module versus a standardized patient module
}

\author{
Kye-Yeung Park, Hoon-Ki Park ${ }^{*}$ (D) and Hwan-Sik Hwang
}

\begin{abstract}
Background: An important barrier to smoking-cessation counseling for physicians is a lack of education at the undergraduate level. Interactive methods such as peer role-play (RP) or modules utilizing standardized patients (SPs) may be effective for medical students to enhance their performance on tobacco cessation counseling. This study compared the effectiveness of a module using SPs to that of a RP module for undergraduate medical students on tobacco cessation counseling.

Methods: This study was conducted over a single week of the family medicine clerkship. One hundred and thirteen fourth-year medical students were randomized into either the SP group or the RP group. A RP module involved a tenminute encounter between the student doctor and the student patient followed by five minutes of feedback from the observer student using a group developed checklist. In a SP module, each student was asked to interview a SP portraying a smoker with willingness to quit. After the encounter, the SP provided five minutes of direct oral feedback to the student. In both modules, the total intervention lasted three-and-half hours and was supervised by faculty staff. Students' objective structured clinical examination (OSCE) scores were evaluated to determine their tobacco cessation counseling skills. Four evaluation periods were conducted at baseline, postintervention, post-clerkship, and before receiving the Korean medical licensing examination (KMLE). Students' smoking knowledge test scores and counseling self-confidence levels at pre- and post-intervention were also compared.
\end{abstract}

Results: In both groups, post-intervention OSCE scores increased significantly compared to baseline (Cohen's $d$ 0.87, $p<0.001$ in SP group; $d 0.77, p<0.001$ in RP group). However, there were no differences between the two groups. Students achieved the highest OSCE score for smoking-cessation counseling before the KMLE. After training, student self-confidence and smoking-knowledge test scores increased significantly, regardless of the type of module. Selfconfidence was higher in the SP group compared with the RP group ( $d 0.37, p=0.01)$.

Conclusions: Peer role-play may be equivalent to the SP method with regard to knowledge and skills reported during smoking-cessation counseling and SP method may be better in self-confidence. Cost and student self-confidence may be important factors when choosing among the teaching methods for smoking-cessation counseling.

Keywords: Undergraduate medical education, Role playing, Standardized patient, Tobacco cessation counseling, Objective structured clinical examination

\footnotetext{
* Correspondence: hoonkp@hanyang.ac.kr

Department of Family Medicine, Hanyang University College of Medicine,

222, Wangsimni-ro, Seongdong-gu, Seoul 04763, South Korea
}

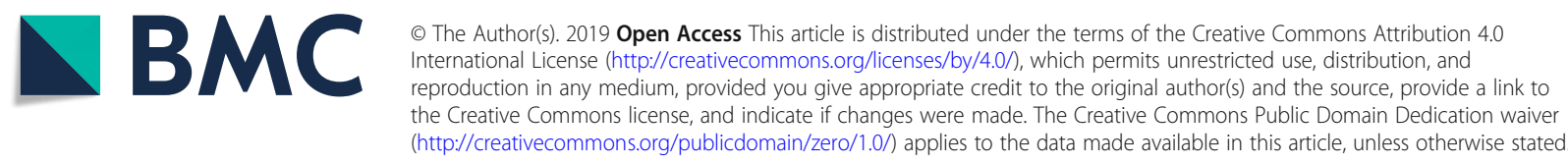




\section{Background}

Smoking is one of the most common preventable causes of death worldwide [1, 2]. In Korea in 2010, 21.3\% of male deaths among all ages occurred due to smoking [3]. Although smoking rates have decreased significantly in many developed countries, Korea's male smoking rate remains higher $(31.4 \%)$ than the average (23.9\%) for the 34 member countries of the Organization for Economic Cooperation and Development (OECD) [4, 5]. Based on large-scale population surveys in Korea in 2016, 30.4\% of men in their thirties and $25.0 \%$ of men in their forties were smokers [5].

About $70 \%$ of smokers report that they would like to quit smoking, but fewer than one in 10 smokers achieved cessation success [6]. While a variety of smoking-cessation aids, such as counseling and pharmacological interventions, are available, two-thirds of smokers use no treatment when trying to quit [6, 7]. Many studies have determined that brief and simple advice about quitting smoking from healthcare professionals can make a difference in quit rates [8, 9]. A systematic review of 17 studies revealed a significant increase in quit rates by a further 1 to $3 \%$ following brief advice to smokers compared to no advice or routine care [10]. Additionally, concurrent use of behavioral counseling interventions and pharmacologic support during smoking cessation can double the rate of successful abstinence [11]. However, medical practitioners raise the subject of smoking with only a small proportion of their smoking patients, even though they are in a uniquely strong position to assist their patients in smoking cessation [12]. The National Health Interview Survey in U.S. has revealed $53 \%$ of workers were not advised to quit smoking by their healthcare providers [13]. A multicenter study in European countries has also shown that about $30 \%$ of general practitioners did not enquire about smoking unless the patient had smoking-related symptoms, though many of them perceived the discussion of smoking cessation as part of their job [14]. The most important barrier for physicians in smoking-cessation interventions is a lack of education at the undergraduate level [15-17]. There is a growing awareness of the necessity for tobacco education for undergraduate medical students and physicians and its important role in improving public health [18-20].

There are several methods for teaching smokingcessation skills to medical students, including role-play, seminars, and rehearsal with simulated patients, and these methods can be combined with several feedback methods, including audiotape feedback, videotape feedback, mutual peer feedback, and standardized patients' (SPs) direct oral feedback [20-22]. Many studies have demonstrated the effectiveness of smoking-cessation teaching methods. Results suggest that interactive methods, such as peer role-play or modules utilizing SPs, may be effective at enhancing knowledge and belief about tobacco-dependence treatment for undergraduate medical students compared with lecture-style methods [20, 22]. Communicationskills-oriented educational methods were shown to affect students' clinical skills and behaviors regarding smokingcessation counseling. One study compared two interactive modules-one involving SPs and one with peer roleplay-for training communication skills to nursing students, and found that the SP-based method was superior to peer role-playing [21]. Another study suggested that role playing provided students with a high level of smoking cessation counseling skills similar to those provided by practicing with SPs [23].

Although two educational modules involving SPs and peer role-play are widely used for teaching patient counseling, there is a lack of evidence from comparisons between the two methods for use in smoking-cessation education. The cost of an SP smoking-cessation practice exercise is more expensive than that of a role-play. Beyond the costs for administrative staff, which is necessary in both methods during the exercise, SP method further costs for training the SPs and payment of salaries [23]. One study comparing the effectiveness of two modules on teaching motivational interviewing found no difference between two modules, in which the primary outcome was the quality of interview [24]. We aimed to compare the effectiveness of a module involving SPs in a one-to-one communication module with direct oral feedback from the SP versus peer role-play with mutual feedback for undergraduate medical students on tobacco cessation counseling. Our study specifically aimed to evaluate the two modules by measuring scores from objective structured clinical examination (OSCE) on tobacco-cessation counseling, students' self-reported questionnaires on self-confidence, written-knowledge test scores on tobacco cessation, and short-term and long-term retention effects after education from one of the two modules.

\section{Method}

\section{Participants}

We enrolled 113 participants which was the full year cohort of fourth-year medical students attending a major medical school in Korea during 2015. The fourth-year medical school curriculum involves clinical rotations, including a family medicine clerkship from March through July. For regular clinical clerkships, students were divided into fourteen small groups (six to nine students per group). This study was conducted during one week of the family medicine clerkship in which smoking-cessation counseling teaching is an integral part. Figure 1 shows the timeline of this study. Both enrollment and retainment rate were $100 \%$ since all 


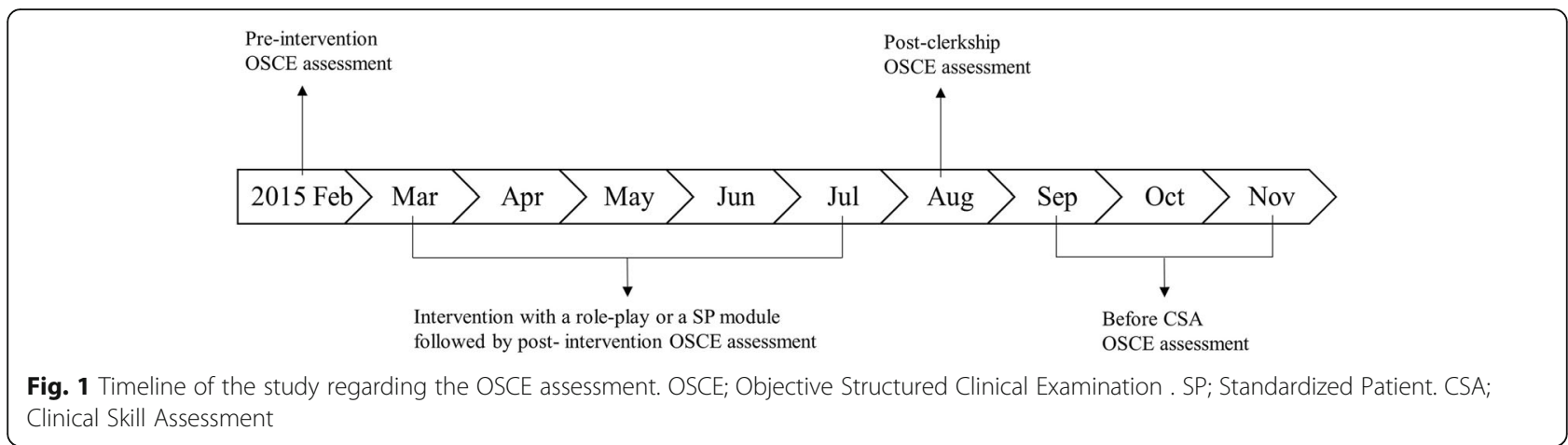

students participated the study and completed all the assessments.

Students gave consent to enter the study before randomization. Students were allocated either to a standardized patients (SPs) group or to a role-play group on the basis of the group randomization by the order of clinical clerkship rotation [25, 26]. Random digit number was produced using Excel $^{\circ}$ software program by the third person. Each group completed the intervention module predetermined by randomization.

To achieve a power of 0.8 with a two-sided significance level of $5 \%$ for a minimum effect size of 0.6 with respect to OSCE scores, a required sample size of 45 for each group was calculated. The effect size was based on the pooled standard deviation of 8.0 estimated by an interim analysis of two intervention groups. As one item score was 4.0 from full marks of 100 points for the OSCE station with 25 checklist items, effect size of 0.6 was equivalent to around the score of 1.2 items.

\section{Pre-intervention}

Students' tobacco-cessation counseling skills were evaluated as a pre-intervention OSCE score to determine baseline performance. As part of the standard curriculum, medical students were assessed according to their clinical skills by the OSCE involving twelve SP encounters in February 2015, a month before the regular clinical clerkships. The scenarios and marking schemes for each OSCE station were developed and agreed by consensus of local experts. Face validity was assessed by the panels developing the stations. Tobacco-cessation counseling occurred in one of the twelve SP encounters. Students were given ten minutes to evaluate and counsel a smoking patient. Prior to the intervention during the family-medicine clerkship, we measured students' baseline knowledge of smoking by written test and their selfconfidence to counsel their own smoker-patients by selfadministered questionnaire on a ten-point Likert scale from 1 to 10 (from $1=$ extremely inconfident to $10=$ extremely confident in smoking cessation counseling). The written test was the questionnaire of 43 items to assess medical students' knowledge of tobacco cessation and treatment for nicotine addiction, which was developed according to previous related literatures [27, 28]. It consisted of four knowledge sections, i.e., smoking epidemiology (4 items), health risks of smoking (19 items), benefits of tobacco cessation (3 items), and treatment of nicotine addiction (17 items). When reliability of the cognitive competence questionnaires was determined by the Rasch model, it was 0.97 for pre-test and 0.95 for post-test, respectively. Local experts in smoking cessation and primary care physicians in the university hospital assessed its face validity as good. To prepare for the intervention, students were instructed to discuss and develop an OSCE checklist in their group. This checklist was utilized to provide each student doctor feedback on his or her performance by a SP or a student observer in each module play.

\section{Peer role-play module}

Students worked in groups of three and alternatively role-played the doctor, the patient, and the observer. Prior to the role-play, each group was instructed to develop a scenario for smoking cessation. Role-play involved a ten-minute encounter followed by five minutes of feedback from the observer of each role-play episode. A group-developed OSCE checklist was used to rate the performance and provide feedback. One cycle of a roleplay took fifteen minutes, which consisted of the tenminute encounter and five minutes of peer feedback. Three cycles of a role-play comprised one round. The first round was conducted using a scenario developed by each group, and then students exchanged the scenario between groups for the second round. Groups of three students proceeded to role-play through three rounds of the cycle as a whole. The total intervention lasted threeand-half hours and was supervised by faculty staff.

\section{SP module}

In this module, two experienced actors were trained as SPs to portray a smoker with a willingness to quit smoking. SPs received in-depth training by the faculty staff 
for about two hours. Students in the SP module did an interview with one female SP and one male SP. Each student was asked to privately counsel a SP in an examination room for ten minutes. Other students observed the interview remotely through cameras placed in the room. After the encounter, every SP provided five minutes of direct oral feedback to the student. Each student had three encounters with a SP and received feedback for each. The total intervention lasted threeand-half hours and was supervised by faculty staff, as for the role-play module.

\section{Post-intervention}

At the end of the family medicine clerkship, following the intervention, students' smoking cessation intervention skills were assessed again with a post-intervention OSCE score. The post-intervention OSCE consisted of a single SP case. This mini-OSCE was used to assess postintervention students' smoking cessation counseling skills. Students were given ten minutes to evaluate and counsel a smoking patient. Same as the pre-intervention, students were administered a post-intervention evaluation for smoking knowledge and self-confidence levels. Also, the survey gauged the students' satisfaction with each module.

After finishing the regular clinical clerkship, students' counseling skills were assessed through a mini-OSCE that evaluated knowledge of a clinical scenario other than smoking cessation. This accounted for a post-clerkship OSCE score that represented the short-term effects of the training. A new scenario used in the assessment was different in terms of the SP's motivational stage toward smoking cessation compared with the post-intervention OSCE scenario, in which the SP was willing to quit smoking. The purpose of the new scenario was to evaluate the transferability of students' counseling ability as well as the short-term effect of the intervention.

Students did take the Clinical Skill Assessment (CSA) of Korean Medical Licensing Examination (KMLE) between September and November. Prior to taking the KMLE-CSA, students were evaluated via a mini-OSCE on smoking-cessation counseling in such a way as to be representative of the long-term effects of the training. All OSCE and mini-OSCEs on tobacco-cessation counseling were scored using a 17 -item behavioral checklist with dichotomous scoring and an 8-item behavioral checklist with a seven-point scale. SPs conducted standardized assessment of students' performances.

\section{Data analysis}

Descriptive statistics were used for the student demographic data. To measure the effects of the two modules on student OSCE scores mean scores for the OSCE preand post-intervention were compared using a paired $\mathrm{t}$ - test. The total OSCE score consisted of four components: patient satisfaction (PS), history taking (HT), patient education (PE), and patient-physician interaction (PPI), of which we compared the difference between preand post-intervention with a paired t-test. Student's t-test was used to compare the OSCE scores, self-confidence ratings, and smoking-knowledge test scores between the SP module and the role-play module groups. To examine the retention effect of the training, pre-intervention OSCE scores, post-intervention OSCE scores, post-clerkship OSCE scores, and OSCE scores before the KMLE-CSA were analyzed using repeated-measures analysis of variance with post-hoc analysis by Bonferroni's method. The assumption of sphericity and equality of covariance matrices were satisfied. Effect sizes were calculated using Cohen's $d$. $P$-values less than 0.05 were considered statistically significant. All analyses were conducted using SPSS, version 21.0 (SPSS Inc., Chicago, IL).

\section{Results}

A total of 113 medical students in their fourth year participated in the study. Average student age was 26.2 years. There were no significant percentage differences in age, sex, and proportion of smokers between the SP module group and the role-play group (Table 1).

Figure. 2A shows the differential effects of the SP module and the role-play module on the students' OSCE scores. In the SP module group, the postintervention OSCE scores increased significantly (Cohen's $d$ 0.87, $p<0.001$ ) compared with the preintervention OSCE scores, along with a significant increase in the HT, PE, and PPI components (component data not shown in the figure). In the role-play group, post-intervention OSCE scores were significantly higher than the pre-intervention scores $(d 0.77, p<0.001)$; the HT and PE components increased significantly. After their training, students' self-confidence and smokingknowledge scores also increased significantly, regardless of module type (all $p<0.001$ ) (Fig. 2B, C).

In the post-intervention comparisons, post-intervention OSCE scores and smoking-knowledge scores were not statistically different between two groups. Student postintervention self-confidence levels were significantly higher in the SP group than in the role-play group $(d 0.37$, $p=0.01$ ), with higher baseline self-confidence levels in the SP group also. Students' satisfaction levels on each module were equivalent between two modules (Table 2).

Figure 3 shows the long-term retention effect as well as the short-term effect of each module. Among the four assessments-pre-intervention OSCE, post-intervention OSCE, post-clerkship OSCE, and OSCE before the KMLE-CSA-students' OSCE scores were highest before the KMLE-CSA in both groups $(p<0.001$ in both groups). In the SP group, the post-clerkship OSCE score 
Table 1 Student demographics $(N=113)$

\begin{tabular}{|c|c|c|c|c|}
\hline & $\begin{array}{l}\text { Students taking the standardized } \\
\text { patient (SP) module } \\
(N=57)\end{array}$ & $\begin{array}{l}\text { Students taking the } \\
\text { peer role-play module } \\
(N=56)\end{array}$ & $\begin{array}{l}\text { Total } \\
(\mathrm{N}=113)\end{array}$ & P-value* \\
\hline Age & $26.5 \pm 3.0$ & $25.9 \pm 2.1$ & $26.2 \pm 2.6$ & 0.23 \\
\hline Sex (male, \%) & $36(63.2)$ & $35(62.5)$ & $71(62.8)$ & 0.94 \\
\hline Smoking status (non-smoker, \%) & $48(84.2)$ & $48(85.7)$ & $96(85.0)$ & 0.74 \\
\hline Alcohol consumption (drinker, \%) & $50(87.7)$ & $49(87.5)$ & 99 (87.6) & 0.12 \\
\hline
\end{tabular}

Values are presented as mean \pm SD or number (\%)

${ }^{a}$ One-to-one communication training with direct oral feedback from the standardized patient

${ }^{\mathrm{b}}$ Training with peer role-playing and mutual feedback

*Student t-test between the case group and the control group

for the new scenario was higher than the preintervention score without significance $(d 0.41, p=0.15)$ (Fig. 3A). In the role-play group, the post-clerkship OSCE score for the new scenario was higher than the pre-intervention score ( $d$ 0.62, $p=0.02)$ (Fig. 3B).
Figure $3 \mathrm{C}$ revealed that there were no significant differences between the two modules for short-term or longterm retention effects $(d 0.35, p=0.06$ in post-clerkship scores; $d$ 0.16, $p=0.38$ in scores before the KMLECSA). There was no significance of group-by-time
(A) OSCE total score

(B) Self-confidence rating

(C) Smoking knowledge test score
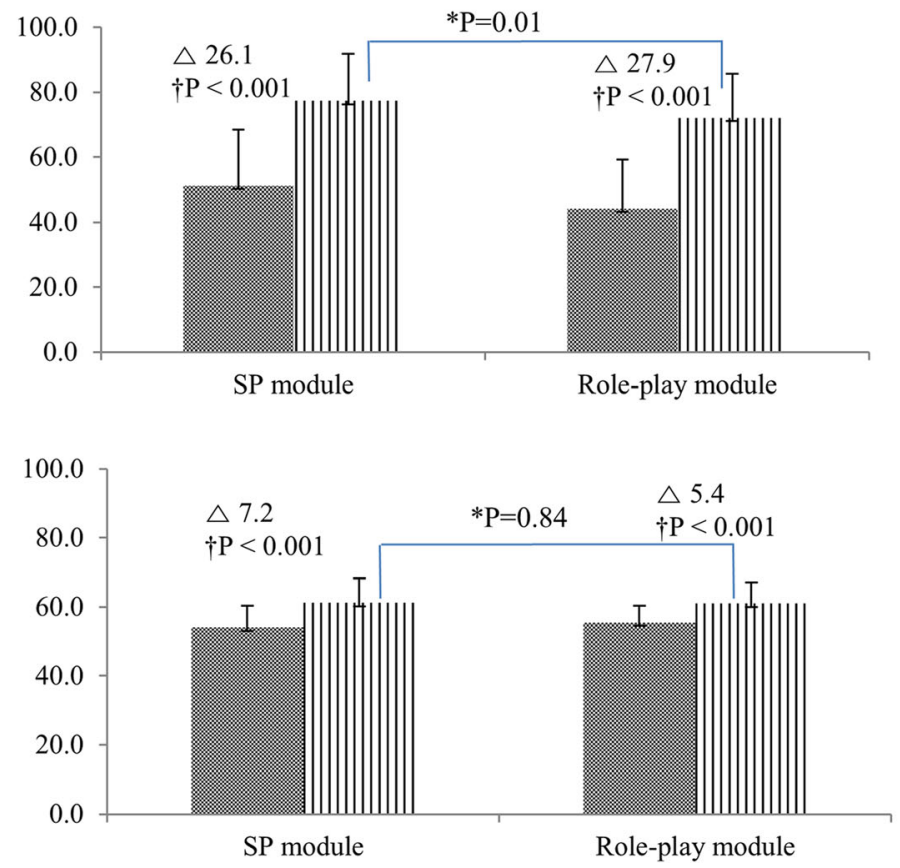

Pre-intervention

II Post-intervention

Pre-intervention

II Post-intervention

: Pre-intervention

II Post-intervention

Fig. 2 Comparison of pre-intervention and post-intervention scores for two groups. (a)OSCE total score. (b)Self-confidence rating. (c)Smoking knowledge test score. SP; Standardized Patient, OSCE; Objective Structured Clinical Examination. ${ }^{*}$-value by independent t-test between a standardized patient module and a role play module. $\mathrm{P}$-value by paired t-test between pre-intervention and post-intervention scores 
Table 2 OSCE scores, self-confidence ratings, knowledge-test scores, and student satisfaction with each module: Comparison of the two groups

\begin{tabular}{|c|c|c|c|c|c|c|}
\hline & \multicolumn{3}{|l|}{ Pre-intervention } & \multicolumn{3}{|l|}{ Post-intervention } \\
\hline & Standardized patient & Role-play & $P$-value ${ }^{*}$ & Standardized patient & Role-play & P-value* \\
\hline \multicolumn{7}{|l|}{ OSCE scores } \\
\hline Patient satisfaction & $66.0 \pm 17.3$ & $66.4 \pm 17.1$ & 0.89 & $69.1 \pm 15.6$ & $68.2 \pm 17.0$ & 0.77 \\
\hline History taking & $77.6 \pm 17.8$ & $80.4 \pm 11.0$ & 0.32 & $87.5 \pm 10.7$ & $86.9 \pm 8.5$ & 0.74 \\
\hline Patient education & $52.2 \pm 18.6$ & $50.7 \pm 18.1$ & 0.66 & $64.0 \pm 16.7$ & $62.1 \pm 16.5$ & 0.53 \\
\hline Patient-physician interaction & $65.8 \pm 10.3$ & $67.6 \pm 10.1$ & 0.35 & $69.1 \pm 10.5$ & $69.6 \pm 10.2$ & 0.79 \\
\hline Total score & $65.7 \pm 10.7$ & $66.7 \pm 8.9$ & 0.58 & $74.1 \pm 8.6$ & $73.4 \pm 8.4$ & 0.64 \\
\hline Self-confidence rating & $51.1 \pm 17.4$ & $44.2 \pm 15.0$ & 0.02 & $77.3 \pm 14.6$ & $72.1 \pm 13.5$ & 0.01 \\
\hline Knowledge test score & $54.0 \pm 6.4$ & $55.5 \pm 4.9$ & 0.21 & $61.2 \pm 7.0$ & $61.0 \pm 6.1$ & 0.84 \\
\hline Student satisfaction & & & & $81.0 \pm 14.9$ & $77.4 \pm 14.7$ & 0.10 \\
\hline
\end{tabular}

OSCE; Objective Structured Clinical Examination

Values are presented as mean $\pm \mathrm{SD}$

*Student t-test of OSCE scores between the two groups

interaction in the OSCE score by repeated-measures ANOVA $(p=0.30)$.

\section{Discussion}

In this study, undergraduate medical students' OSCE scores for tobacco-cessation counseling increased significantly after education by both the SP and peer role-play modules. The HT and PE components of the OSCE scores improved significantly after both modules, while the PPI component improved significantly after the SP module only. Students improved significantly in smoking knowledge according to written test scores as well as in self-confidence after both modules. Although there were no differences between the two modules with regard to post-intervention OSCE scores or post-intervention smoking-knowledge scores, the SP module for tobaccocessation education yielded better results for student self-confidence than the peer role-play module. Students were equally satisfied with their education modules. The short-term and long-term effects on retention of tobacco-cessation education were seen from both modules after two to eight months.

For successful smoking cessation, individualized smokingcessation counseling and pharmacological intervention are required based on different behavioral stages of smoking cessation [29]. To achieve successful cessation, appropriate

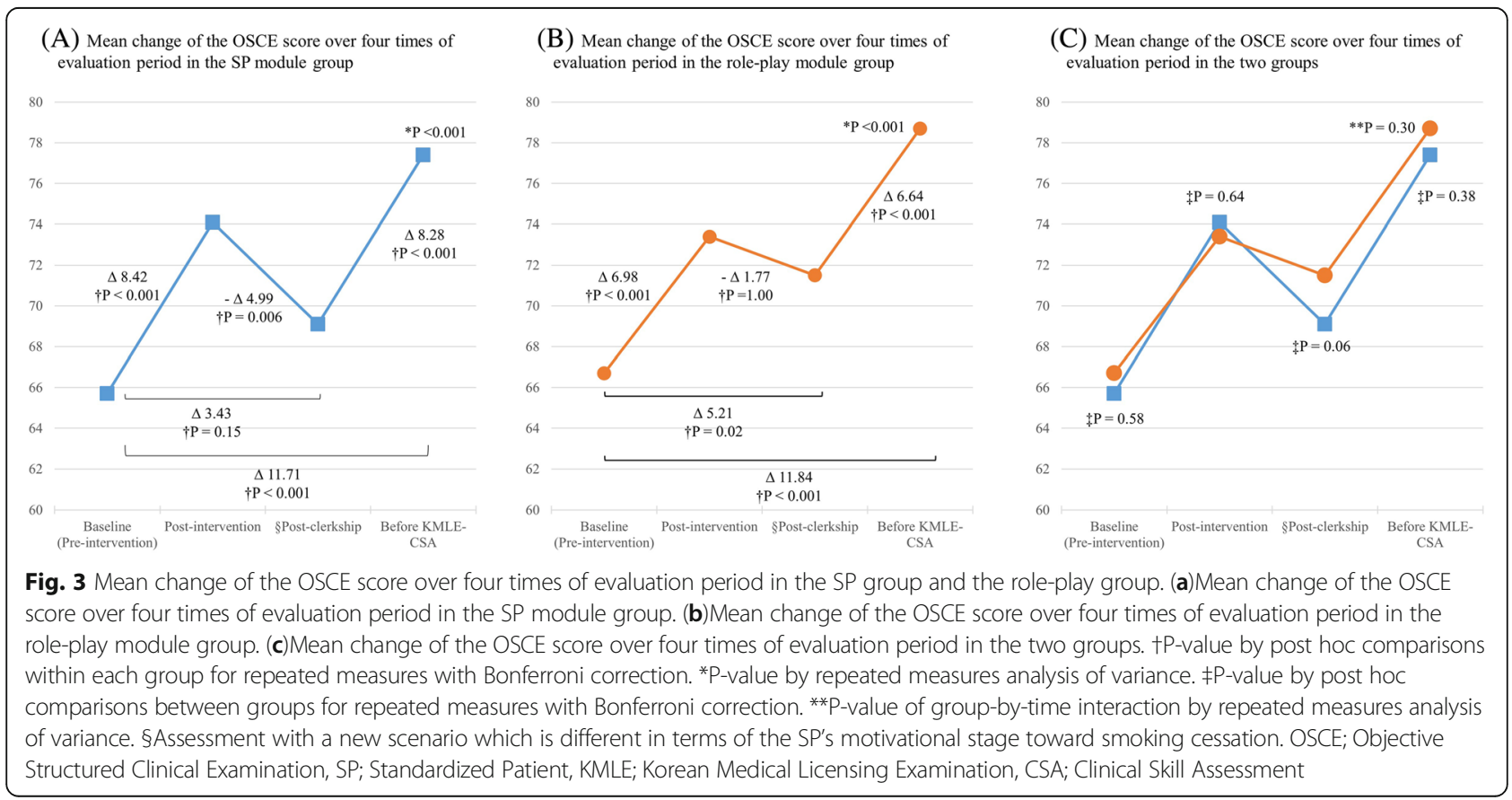


education and training are needed at the undergraduate level; thus, physicians should be well-prepared in terms of both smoking knowledge and interview skills [30]. There are several approaches to smoking-cessation training, which can be classified into traditional methods, such as didactic lectures or handouts, and interactive or practical methods, such as case reports, problem-based learning, role-play, and interviewing a standardized patient $[19,20,30,31]$.

The two modules in our study utilized active learning or practical skills for smoking-cessation counseling training. A previous study demonstrated that passive learning methods, such as didactic lectures, as well as active-learning methods, can help medical students learn the basic principles of smoking-cessation counseling [32-34]. In our study, medical students' smokingcessation knowledge increased after both the role-play module and the SP module. Since a lack of perceived self-confidence has been considered to be one of the major barriers in tobacco-cessation counseling, educational modules that improve medical student selfconfidence have been increasingly recommended [35]. As for smoking-cessation counseling education worldwide, the percentage of schools that use an interactive method or patient-centered counseling was reported to be low-only one third of medical schools [31]. Also, practical-skills training for smoking-cessation counseling was reported to be insufficient in the UK [19]. Interactive learning methods, rather than didactic lectures, have been reported to improve the communication skills and self-confidence of medical students during their tobacco-cessation counseling [20,22, 30]. Students in our study showed an increase in self-confidence after both modules, although it was higher in students who were educated with the SP module than the role-play module. Although students in the SP module group felt more confident in smoking cessation counseling, however, this self-perceived confidence didn't impact on learning outcomes such as OSCE scores.

Teaching methods involving role-play or SPs have both strengths and weaknesses. Using SPs to teach and evaluate communication skills provides medical students an opportunity to practice skills in a safe and relatively unthreatening environment [36]. Students can repeatedly prepare for an actual clinical problem through SP encounters and be objectively assessed on their communication skills [37, 38]. Also, using SPs can achieve uniformity in case scenarios, in addition to the potential benefits of receiving SP feedback [39]. However, organizing SP modules is costly and complex [40]. Compared with the SP module, peer role-play requires few resources but may not be taken seriously by students [21]. In the peer-role play module, students may feel a greater burden of the training as a result of developing and learning a scenario and exchanging the role of doctor and patient among each other. However, students can experience the role of a patient in the peer role-play module, but not in the SP module. Playing the role of a patient may help students improve their patient counseling skills and deepen their education [41]. The potential effectiveness of peer feedback with role-play for developing smoking-cessation skills has been reported to be at least equal to the SP module [20, 42]. In this study, medical students who were provided with peer role-play practice were found to improve significantly in their self-confidence and knowledge of smoking cessation. This suggests that each medical school can choose an appropriate active-learning method for teaching smokingcessation counseling. For example, if there is a sufficient budget, the SP module may be desirable; however, for smaller budgets, the role-play module can also be an effective training tool for student smoking-cessation counseling. For practical purposes, it was necessary to evaluate how the two modules yielded an increase in the OSCE score of smoking-cessation counseling, since medical students must complete the OSCE for their medical license examination. One study demonstrated that education using interactive teaching methods, including SP or role-play, did not yield higher OSCE scores than the control group [30]. However, in other studies that evaluated the role-play method, the educational effect was reflected in the OSCE score of dental student smoking-cessation counseling [42, 43]. In this study, the post-intervention OSCE scores of medical students were significantly higher than the pre-intervention scores for both modules, and they reflect the short-term effect of educational training. Comparisons of post-intervention OSCE scores in each module were not significantly different. However, it is noteworthy that both modules showed a significant increase in the HT and PE components of the OSCE score, as well as an increase in the PPI after the SP module only. The differential effects of these components reflect the impact of interactive counseling education on medical students. Meanwhile, the post-clerkship OSCE scores for the scenario that was different from the other three OSCE were higher than in the pre-intervention scores but lower than the post-intervention scores. The scores before the KMLECSA, the final OSCE scores, were the highest among the four evaluation periods. This may be attributable to the effect of students' self-directed learning ahead of the KMLE with repeated role-play and peer feedback, in addition to the long-term retention effect of education in each module. Also, there is a possibility that an information-sharing effect among students may exist. In every assessment over the four time periods, students were tested sequentially and they knew that those OSCE scores were being graded. This explains the potential impact of the students' goal orientation as well as the self-study other than the module effect on the final scores around the KMLE assessment. 
One limitation of this study may be its limited generalizability, because it was conducted at a single medical school. The assessment using a single OSCE case may further limit the generalizability when considering variations in smoking patients' readiness to quit. Also, the different timing of the assessments for each group may have affected the objective measurement of OSCE scores due to information-sharing behavior of the students. The clerkship experience during the semester may have influenced students' self-assessment of their self-confidence. In addition, allocation concealment or blinding could not be performed due to the nature of the education course and the study design. Therefore, students in the SP module group could peer-role play or vice versa. All students would have done self-directed learning for smoking cessation counseling in the end to prepare for the KMLE. This could illustrate another consequence of bias. Finally, since the students of role-play module group developed their own scenario, they all played patients at a different stage of change compared to the students of SP group. That would also bias the results.

Despite these limitations, our findings highlight the effectiveness of smoking-cessation counseling training in the medical school curriculum. These findings provide some evidence that peer role-play may be an equivalent educational method in terms of smoking cessation counseling skills and knowledge compared to the SP method. Our study suggests that it is necessary for medical schools to choose one or the other educational module for teaching smoking-cessation counseling, considering cost and the effectiveness of a module.

\section{Conclusions}

Appropriate smoking cessation counseling education is required at the undergraduate level for physicians to have counseling skills. This study not only compared the role play module to SP module in terms of smoking knowledge test score, self confidence level, and OSCE score, but also analyzed the long-term effects of education. Both modules were effective in increasing the OSCE score, self-confidence and knowledge score of the smoking cessation counseling. Above all, the role play module was equivalent in several aspects to the SP module. It will be important to compare the two methods for teaching smoking cessation counseling according to educational conditions.

\footnotetext{
Abbreviations

CSA: Clinical Skill Assessment; HT: History Taking; KMLE: Korean Medical Licensing Examination; OSCE: Objective Structured Clinical Examination PE: Patient Education; PPI: Patient-Physician Interaction; PS: Patient Satisfaction; SP: Standardized Patients
}

\section{Author's contributions}

HKP determined the design of the study, planned the methodology and analyzed the results. KYP and HSH undertook the search, and contributed to the summation of findings and discussion. KYP is the primary author. All authors critically reviewed the draft of the manuscript. HKP revised the manuscript for important intellectual content. All authors have approved the final version of the manuscript.

\section{Funding}

This work was supported by the research fund of Hanyang University (HY2014). The funders had no role in the design of the study, data collection and analysis, or preparation of the manuscript.

\section{Availability of data and materials}

The datasets and materials can be obtained from the corresponding author upon reasonable request.

\section{Ethics approval and consent to participate}

This study was approved by the Institutional Review Board on Human Subjects Research and the Ethics Committee of Hanyang University Hospital. Written informed consent was obtained from all subjects.

\section{Consent for publication}

Not applicable.

\section{Competing interests}

The authors declare that they have no competing interests.

Received: 26 June 2018 Accepted: 12 June 2019

Published online: 25 June 2019

\section{References}

1. World Health Organization. WHO global report on trends in prevalence of tobacco smoking 2015. World Health Organization; 2015.

2. Centers for Disease Control and Prevention. Best Practices for Comprehensive Tobacco Control Programs. 2014. https://www.cdc.gov/ tobacco/stateandcommunity/best_practices/pdfs/2014/comprehensive.pdf. Accessed 22 Jun 2018.

3. Eriksen M, Mackay J, Schluger NW, Islami F, Drope J. Worldlungfoundation, et al. the tobacco atlas. 5th edition. Atlanta. Am Cancer Soc. 2015.

4. Organization for Economic Cooperation and Development (OECD). Health at a Glance 2015 Demographic trends. 2015.

5. Korea Centers for Disease Control and Prevention. The seventh Korea National Health and nutrition examination survey (KNHANES VII-1). 2016. Available at http://knhanes.cdc.go.kr/.

6. Babb S, Malarcher A, Schauer G, Asman K, Jamal A. Quitting smoking among adults - United States, 2000-2015. MMWR Morb Mortal Wkly Rep. 2017:65:1457-64.

7. Rigotti NA. Strategies to help a smoker who is struggling to quit. JAMA. 2012;308:1573-80.

8. Jerome L. Schwartz NCl. U. S. Review and evaluation of smoking cessation methods: the United States and Canada, 1978-1985. Division of Cancer Prevention and Control, National Cancer Institute, U.S. Dept. of Health and Human Services, Public Health Service, National Institutes of Health, 1987; 1987.

9. Wilson DM, Taylor DW, Gilbert JR, Best JA, Lindsay EA, Willms DG, et al. A randomized trial of a family physician intervention for smoking cessation. JAMA. 1988;260:1570-4.

10. Stead LF, Buitrago D, Preciado N, Sanchez G, Hartmann-Boyce J, Lancaster T. Physician advice for smoking cessation. Cochrane Database Syst Rev 2013;5 https://doi.org/10.1002/14651858. CD000165.pub3.

11. Larzelere M, Williams D. Promoting smoking cessation - American family physician. Am Fam Physician. 2012;85:591-8

12. Çakir B, Tas A, Sanver TM, Aslan D. Doctor's enquiry: an opportunity for promoting smoking cessation-findings from global adult tobacco surveys in Europe. Eur J Pub Health. 2017;27:921-5.

13. Helgason AR, Lund KE. General practitioners' perceived barriers to smoking cessation, results from four Nordic countries. Scand J Public Health. 2002;30: $141-7$.

14. Lee DJ, Fleming LE, McCollister KE, Caban AJ, Arheart KL, LeBlanc WG, et al. Healthcare provider smoking cessation advice among US worker groups. Tob Control. 2007;16:325-8. 
15. Godshall W. The most compelling smoking cessation incentive a doctor can offer. Tob Control. 1993:2:237-8.

16. Twardella $\mathrm{D}$, Brenner $\mathrm{H}$. Lack of training as a central barrier to the promotion of smoking cessation: a survey among general practitioners in Germany. Eur J Pub Health. 2005;15:140-5.

17. Sharpe T, Alsahlanee A, Ward KD, Doyle F. Systematic review of clinicianreported barriers to provision of smoking cessation interventions in hospital inpatient settings. J Smok Cessat. 2018;13:233-43.

18. Olano-Espinosa E, Matilla-Pardo B, Minue C, Anton E, Gomez-Gascon T, Ayesta FJ. Effectiveness of a health professional training program for treatment of tobacco addiction. Nicotine Tob Res. 2013;15:1682-9.

19. Raupach T, Al-Harbi G, McNeill A, Bobak A, McEwen A. Smoking cessation education and training in U.K. medical schools: a National Survey. Nicotine Tob Res. 2015;17:372-5.

20. Roche AM, Eccleston P, Sanson-Fisher R. Teaching smoking cessation skills to senior medical students: a block-randomized controlled trial of four different approaches. Prev Med (Baltim). 1996;25:251-8.

21. Schlegel C, Woermann U, Shaha M, Rethans J-J, van der Vleuten C. Effects of communication training on real practice performance: a role-play module versus a standardized patient module. J Nurs Educ. 2012;51:16-22.

22. Singleton JA, Carrico RM, Myers JA, Scott DA, Wilson RW, Worth CT. Tobacco cessation treatment education for dental students using standardized patients. J Dent Educ. 2014;78:895-905.

23. Papadakis MA, Croughan-Minihane M, Fromm LJ, Wilkie HA, Ernster VL. A comparison of two methods to teach smoking-cessation techniques to medical students. Acad Med. 1997;72:725-7.

24. Mounsey AL, Bovbjerg V, White L, Gazewood J. Do students develop better motivational interviewing skills through role-play with standardised patients or with student colleagues? Med Educ. 2006;40:775-80.

25. Murray DM, Varnell SP, Blitstein JL. Design and analysis of grouprandomized trials: a review of recent methodological developments. Am J Public Health. 2004;94:423-32.

26. Campbell MK, Elbourne DR, Altman DG. CONSORT group. CONSORT statement: extension to cluster randomised trials. BMJ. 2004;328:702-8.

27. Springer CM, Tannert Niang KM, Matte TD, Miller N, Bassett MT, Frieden TR. Do medical students know enough about smoking to help their future patients? Assessment of new York City fourth-year medical students' knowledge of tobacco cessation and treatment for nicotine addiction. Acad Med. 2008;83:982-9.

28. Grassi MC, Chiamulera C, Baraldo M, Culasso F, Ferketich AK, Raupach T, et al. Cigarette smoking knowledge and perceptions among students in four Italian medical schools. Nicotine Tob Res. 2012;14:1065-72.

29. Lancaster T, Stead LF. Individual behavioural counselling for smoking cessation. Cochrane Database Syst Rev. 2017;(2017):CD001292.

30. Ockene JK, Hayes RB, Churchill LC, Crawford SL, Jolicoeur DG, Murray DM, et al. Teaching medical students to help patients quit smoking: outcomes of a 10school randomized controlled trial. J Gen Intern Med. 2016:31:172-81.

31. Richmond R, Zwar N, Taylor R, Hunnisett J, Hyslop F. Teaching about tobacco in medical schools: a worldwide study. Drug Alcohol Rev. 2009:28:484-97.

32. Roche AM, Eccleston P, Jordan D. Smoking-related knowledge and attitudes of senior Australian medical students. Tob Control. 1996:5:271-9.

33. Chung TWH, Lam TH, Cheng YH. Knowledge and attitudes about smoking in medical students before and after a tobacco seminar. Med Educ. 1996;30: 290-5.

34. Cleland J, Lee G, Friend J, Osman L. Teaching smoking cessation knowledge to second-year undergraduates. Med Teach. 2005;27:655-7.

35. Kottke TE, Willms DG, Solberg LI, Brekke ML. Physician-delivered smoking cessation advice: issues identified during ethnographic interviews. Tob Control. 1994;3:46-9.

36. Long-Bellil LM, Robey KL, Graham CL, Minihan PM, Smeltzer SC, Kahn P. Teaching medical students about disability: the use of standardized patients. Acad Med. 2011;86:1163-70.

37. Wehbe-Janek H, Song J, Shabahang M. An evaluation of the usefulness of the standardized patient methodology in the assessment of surgery residents' communication skills. J Surg Educ. 2011;68:172-7.

38. Yedidia MJ, Gillespie CC, Kachur E, Schwartz MD, Ockene J, Chepaitis AE, et al. Effect of communications training on medical student performance. $J$ Am Med Assoc. 2003;290:1157-65.

39. Doyle Howley L, Martindale J. The efficacy of standardized patient feedback in clinical teaching: a mixed methods analysis. Med Educ Online. 2004;9:4356
40. Perkowski-Rogers LC, Pohl HS. Planning standardized patient programs: case development, patient training, and costs. Teach Learn Med. 1994;6:6-14.

41. Bosse HM, Schultz JH, Nickel M, Lutz T, Möltner A, Jünger J, et al. The effect of using standardized patients or peer role play on ratings of undergraduate communication training: a randomized controlled trial. Patient Educ Couns. 2012:87:300-6.

42. Fernandez K, Pandve HT, Debnath DJ. Use of interactive teaching methods in tobacco cessation program and examine it by using objective structured clinical exam. J Educ Health Promot. 2013;2:28.

43. Romito L, Schrader S, Zahl D. Using experiential learning and OSCEs to teach and assess tobacco dependence education with first-year dental students. J Dent Educ. 2014;78:703-13.

\section{Publisher's Note}

Springer Nature remains neutral with regard to jurisdictional claims in published maps and institutional affiliations.
Ready to submit your research? Choose BMC and benefit from:

- fast, convenient online submission

- thorough peer review by experienced researchers in your field

- rapid publication on acceptance

- support for research data, including large and complex data types

- gold Open Access which fosters wider collaboration and increased citations

- maximum visibility for your research: over $100 \mathrm{M}$ website views per year

At $\mathrm{BMC}$, research is always in progress.

Learn more biomedcentral.com/submissions 